DOI: $10.2478 /$ lpts-2019-0007

\title{
$V$-FUNCTION METHOD: SOME SOLUTIONS OF DIRECT AND INVERSE DYNAMICS PROBLEMS IN A NEW STATEMENT
}

\author{
Nail T. Valishin \\ Department of Special Mathematics, Kazan National Research Technical \\ University named after A.N. Tupolev, 10 K. Marx Str., 420111, Kazan, RUSSIA \\ vnailt@yandex.ru \\ Fan T. Valishin \\ Philosophy Methodology Center of Dynamism of Tatarstan Academy of Sciences, \\ 20 Bauman Str., 420111, Kazan, RUSSIA \\ dinamism@yandex.ru
}

\begin{abstract}
Based on the $V$-function method, the properties of wave nature of object motion are studied for object uniform motion with constant speed and for harmonic oscillator. It follows from the $V$-function method that object wave motion is inseparably linked with its trajectory motion. The $V$-function method consists of the principle of local variation and a new statement of the direct and inverse dynamics problems. The proposed approach made it possible to make the optico-mechanical analogy that obtained a new continuation. A comparison is made with the results obtained by Schrödinger for a harmonic oscillator.
\end{abstract}

Keywords: optico-mechanical analogy, harmonic oscillator, variation principle, wave equation, wave function

\section{INTRODUCTION}

It is known that wave-particle duality is embedded in quantum mechanics. A quantum object manifests itself as a particle in some experiments while in other ones it behaves like a wave. This duality is fixed in quantum mechanics by the Heisenberg uncertainty principle [1]. Moreover, just this circumstance makes it possible to make the optico-mechanical analogy (that still remains topical [2]-[4]) based on the existing variation principles at a level of geometrical optics only. The continuing attempts to understand the paradoxical display of wave-corpuscle duality in electron (and other microparticles) motion also promote generation of new theories developing the de Broglie's pilot-wave concept [5]-[8].

In this study, we advance a novel approach (based on the wave-corpuscle monism) to explain the quantum object nature. We propose such description of physical reality in which trajectory motion of an object is inseparably linked with its wave motion. In this case, it is assumed that particle motion is determined by 
a physical wave $V(x, t)$, and presence of particle trajectories indicates the fact of particle existence.

\section{MATERIALS AND METHODS}

The classical approach used when developing quantum mechanics is based on description of reality using only the experimentally observed quantities. The theory developed by us is based on the process-state concept introduced to describe the essence and mode of electron existence. Such a concept is initially formulated based on the dynamism strategy [9] in which motion (process) is the essence of reality, while a trajectory (state) is the mode of reality existence. The process-state concept made it possible to formulate the principle of local variation and implement a novel statement of the direct and inverse dynamics problems [10], [11] that are components of the $V$-function method.

\subsection{The V-function Method}

Let us introduce a vector of the phase coordinates $x(t)=\left(x_{1}, x_{2}, \ldots, x_{n}\right)^{T}$; $x \in R^{n}, R^{n}$ is the $n$-dimensional Euclidean space, and time $t \in T$. We consider a differential equation system:

$$
\dot{x}=f(x) \text {. }
$$

The right-hand sides of $f(x)$ are vector-functions that are continuous in all their arguments. They have continuous and module limited partial derivatives $\frac{\partial f}{\partial:}$.

Variation of speed (rate) of the $V$-function change transforms the object from some state to a new state. Following is formulation of the principle of local variation: Of all the possible transitions to a new state, that one is realized at which the speed of wave function $\mathrm{V}(\mathrm{x}, \mathrm{t})$ change takes stationary value at each instant.

$$
\delta\left(\frac{d V}{d t}\right)=0
$$

Let us consider the total variation of rate of wave function change:

$$
\Delta\left(\frac{d V}{d t}\right)=\delta\left(\frac{d V}{d t}\right)+\frac{d}{d t}\left(\frac{d V}{d t}\right) \Delta t, \quad(\Delta t=d t)
$$

where

$$
\frac{d}{d t}=\frac{\partial}{\partial t}+\frac{\partial}{\partial x}^{T} \frac{d x}{d t} .
$$


It is assumed that the wave function ( $V$-function) is a one-valued finite piecewise continuous function satisfying the following equation:

$$
\frac{\partial^{2} V(x, t)}{\partial t^{2}}-\sum_{i, j=1}^{n} \frac{\partial^{2} V(x, t)}{\partial x_{i} \partial x_{j}} f_{i}(x) f_{j}(x)=\sum_{i=1}^{n} \frac{\partial V(x, t)}{\partial x_{i}} \frac{d f_{i}(x)}{d t},
$$

where

$f_{i}(x)$ are components of the $n$-variate vector-function of the right-hand sides of object motion Eq. (1).

Theorem I. A necessary and sufficient condition for transferring to a new state is the existence of V-function such as

$$
\Delta\left(\frac{d V}{d t}\right)=0
$$

Theorem II. An object motion Eq. (1) occurs so that at every instant the phase velocity vector is codirectional with the wave function gradient, i.e.,

$$
\frac{\partial V^{T}}{\partial x} f=|\lambda \| \dot{x}|
$$

The conclusion from Theorem II is that object motion is operated by a wave according to the de Broglie's pilot-wave concept [5], [6].

\subsection{Statement of the Direct and Inverse Dynamics Problems Based on the Principle of Local Variation}

The direct dynamics problem based on the $V$-function method is stated as follows: It is required to determine the wave function $V(x, t)$ that meets Eq. (5) from the specified differential equations describing the trajectory of object motion Eq. (1).

The edge conditions for Eq. (5) are obtained from the connectedness condition for the object wave motion with its trajectory motion and from Theorems I and II. The connectedness conditions for wave and trajectory specify the initial condition for wave function:

$$
\left.V(x, t)\right|_{t=0}=V(x, 0)=0,
$$

and the boundary condition for wave function:

$$
\left.V(x, t)\right|_{x=0}=V(0, t)=0 .
$$

The two other conditions result from Theorems I and II. From Theorem I 


$$
\Delta\left(\frac{d V}{d t}\right)=\frac{d}{d t}\left({\frac{\partial V^{\mathrm{T}}}{\partial x}}^{\mathrm{T}} \delta x\right)+\frac{d}{d t}\left(\frac{\partial V}{\partial t}+{\frac{\partial V^{\mathrm{T}}}{\partial x}}^{\dot{x}}\right) d t=0
$$

we get:

$$
\frac{d}{d t}\left(\frac{\partial V}{\partial t}\right)=0
$$

As a result, the second initial condition for Eq. (5) is as follows:

$$
\left.\frac{\partial V(x, t)}{\partial t}\right|_{t=0}=\frac{\partial V(x, 0)}{\partial t}=\text { const. }
$$

The following equality results from Theorem II:

$$
\frac{\partial V}{\partial x}=k^{-1} \dot{x}
$$

The second boundary condition results from the equality Eq. (13):

$$
\left.\frac{\partial V(x, t)}{\partial x}\right|_{x=0}=\frac{\partial V(0, t)}{\partial x}=k^{-1} \dot{x}(t)=k^{-1} f(x=0)
$$

The inverse dynamics problem is specified as follows: It is required to determine differential equations of object motion (Eq. (1)) for a known wave function $V(x, t)$ that obeys Eq. (5).

For the sake of convenience, let us write Eq. (5) as follows:

$$
\frac{\partial^{2} V}{\partial t^{2}}-\dot{x}^{T} W \dot{x}=\frac{\partial V^{T}}{\partial x} \frac{d \dot{x}}{d t}, \quad W=\left[\frac{\partial^{2} V(x, t)}{\partial x_{i} \partial x_{j}}\right] .
$$

Knowing the wave function $V(x, t)$, we obtain from Eq. (7) solution of the inverse dynamics problem as

$$
\dot{x}_{i}=k \frac{\partial V}{\partial x_{i}} .
$$

It can be shown from Eq. (10) and Theorem II that the following equality takes place: 


$$
\frac{\partial V^{T}}{\partial x} \frac{d}{d t} \dot{x}=0
$$

As a result, Eq. (15) becomes

$$
\frac{\partial^{2} V}{\partial t^{2}}-\dot{x}^{T} W \dot{x}=0
$$

The above results are used to make the optico-mechanical analogy and simulate trajectory-wave motion of a harmonic oscillator.

\section{RESULTS AND DISCUSSION}

\subsection{Solving the Direct and Inverse Dynamics Problems}

Let us consider solving the direct and inverse dynamics problems for object uniform motion with constant speed. In this case, Eqs. (1) and (5) are:

$$
\begin{aligned}
& \dot{x}=\vartheta \\
& \frac{\partial^{2} V}{\partial t^{2}}-\dot{x}^{2} \frac{\partial^{2} V(x, t)}{\partial x^{2}}=0,
\end{aligned}
$$

With allowance made for Eq. (19), we obtain from Eq. (20) the classical wave equation:

$$
\frac{\partial^{2} V}{\partial t^{2}}-\vartheta^{2} \frac{\partial^{2} V(x, t)}{\partial x^{2}}=0,
$$

for which the conditions Eqs. (8) and (9) remain invariant, while Eqs. (12) and (14) become:

$$
\begin{aligned}
& \left.\frac{\partial V(x, t)}{\partial t}\right|_{t=0}=\frac{\partial V(x, 0)}{\partial t}=\widetilde{C}_{1}, \\
& \left.\frac{\partial V(x, t)}{\partial x}\right|_{x=0}=\frac{\partial V(0, t)}{\partial x}=\widetilde{C}_{2} .
\end{aligned}
$$

To solve Eq. (21) with the specified edge conditions, we apply the variable separation method $V(x, t)=\varphi(t) \psi(x)$ : 


$$
\begin{aligned}
& \frac{\ddot{\varphi}(t)}{\varphi(t)}=\vartheta^{2} \frac{\psi^{\prime \prime}(x)}{\psi(x)}=-\omega^{2} \\
& \ddot{\varphi}(t)+\omega^{2} \varphi(t)=0 \\
& \psi^{\prime \prime}(x)+\frac{\omega^{2}}{\vartheta^{2}} \psi(x)=0
\end{aligned}
$$

As a result, the general solution of Eq. (21) is as follows:

$$
V(x, t)=\left(C_{1} e^{-i \omega t}+C_{2} e^{i \omega t}\right)\left(C_{3} e^{-i \frac{\omega}{\vartheta} x}+C_{4} e^{i \frac{\omega}{\vartheta} x}\right) .
$$

The constants in Eq. (25) will be expressed through the initial and boundary conditions Eqs. (8), (9) and (23), i.e.,

$$
\begin{aligned}
& \varphi(0) \psi(x)=C_{1}+C_{2}=0 \\
& \dot{\varphi}(0) \psi(x)=\left(-i \omega C_{1}+i \omega C_{2}\right) \psi(x)=\widetilde{C}_{1} \Rightarrow \dot{\varphi}(0)=\bar{C}_{1} \\
& \varphi(t) \psi(0)=C_{3}+C_{4}=0 \\
& \varphi(t) \psi^{\prime}(0)=\varphi(t)\left(\frac{-i \omega}{\vartheta} C_{3}+\frac{i \omega}{\vartheta} C_{4}\right)=\widetilde{C}_{2} \Rightarrow \psi^{\prime}(0)=\bar{C}_{2}
\end{aligned} .
$$

It follows from Eq. (26) that:

$$
\begin{aligned}
& C_{1}=-C_{2}, C_{2}=\frac{\bar{C}_{1}}{i \omega} \\
& C_{3}=-C_{4}, C_{4}=\frac{\vartheta \bar{C}_{2}}{i \omega} .
\end{aligned}
$$

By substituting the obtained constants into Eq. (25), we get:

$$
\begin{aligned}
& V(x, t)=\left(\frac{-\overline{C_{1}}}{i \omega} e^{-i \omega t}+\frac{\overline{C_{1}}}{i \omega} e^{i \omega t}\right)\left(\frac{-\vartheta \overline{C_{2}}}{i \omega} e^{-i \frac{\omega}{\vartheta} x}+\right. \\
& \left.+\frac{\vartheta \overline{C_{2}}}{i \omega} e^{i \frac{\omega}{\vartheta} x}\right)=-\frac{\vartheta \overline{C_{2}} \overline{C_{1}}}{\omega^{2}} e^{-i\left(\omega t+\frac{\omega}{\vartheta} x\right)}+\frac{\vartheta \overline{C_{2}} \overline{C_{1}}}{\omega^{2}} e^{i\left(\omega t-\frac{\omega}{\vartheta} x\right)}+ \\
& +\frac{\vartheta \overline{C_{2}} \overline{C_{1}}}{\omega^{2}} e^{-i\left(\omega t-\frac{\omega}{\vartheta} x\right)}-\frac{\vartheta \overline{C_{2}} \overline{C_{1}}}{\omega^{2}} e^{i\left(\omega t+\frac{\omega}{\vartheta} x\right)}= \\
& =-\frac{\vartheta \overline{C_{2}} \overline{C_{1}}}{\omega^{2}} e^{ \pm i\left(\omega t+\frac{\omega}{\vartheta} x\right)}+\frac{\vartheta \overline{C_{2}} \overline{C_{1}}}{\omega^{2}} e^{ \pm i\left(\omega t-\frac{\omega}{\vartheta} x\right)}
\end{aligned}
$$


The solution is in the form of a plane wave. In what follows we consider wave propagation only in the direction of object motion. Then from Eq. (28) we get the $V$-function as

$$
V(x, t)=\frac{\vartheta \bar{C}_{2} \bar{C}_{1}}{\omega^{2}} e^{ \pm i\left(\frac{\omega}{\vartheta} x-\omega t\right)}=A e^{ \pm i\left(\frac{\omega}{\vartheta} x-\omega t\right)}
$$

\subsection{Continuation of the Optico-mechanical Analogy}

Based on the inverse dynamics problem, one can see that the trajectory motion of a particle (at $n=1$ ), as follows from Eq. (16), has to satisfy Eq. (20):

$$
\dot{x}=k \frac{\partial V}{\partial x} .
$$

Thus, all this makes it possible to draw the following analogy between wave and particle:

$$
\begin{aligned}
& \vartheta=\vartheta, \omega=\frac{m \vartheta^{2}}{\hbar}=\frac{2 E}{\hbar}, \\
& \lambda=\frac{h}{m \vartheta}, A=\hbar .
\end{aligned}
$$

It follows from the first relation in Eq. (30) that wave phase velocity is equal to particle velocity. It is known from quantum mechanics that group velocity of the de Broglie waves is equal to particle velocity. The second relation in Eq. (30) shows relationship between particle energy and wave carrier frequency. Based on the third relation in Eq. (30), the wavelength $\lambda$ is determined by the particle momentum. And this relation coincides with the famous de Broglie relation. As a result, particle position is determined by the wave node. In this case, wave guides particle; at the same time, particle generates wave.

\subsection{A Linear Harmonic Oscillator}

Let us consider a linear harmonic oscillator. From Eq. (31) of trajectory motion of object (particle):

$$
m \ddot{x}=-k x \text {. }
$$

The trajectory motion of object (particle) is joined with wave motion described by Eq. (23) and at $n=1$ is: 
$\frac{\partial^{2} V}{\partial t^{2}}-\dot{x}^{2} \frac{\partial^{2} V(x, t)}{\partial x^{2}}=0$.

As a result, we get solution as a function of time:

$$
x(t)=\frac{\vartheta_{0}}{\omega_{0}} \sin \omega_{0} t,
$$

where

$$
\omega_{0}=\sqrt{\frac{k}{m}} .
$$

The object motion speed will be determined from time derivative of this solution.

In our case, separation of variables is performed in such a way:

$$
\frac{\ddot{\varphi}(t)}{\dot{x}^{2}(t) \varphi(t)}=\frac{\psi^{\prime \prime}(x)}{\psi(x)}=-\frac{1}{\lambda^{2}}
$$

where $\lambda$ is a constant. For this we have:

$$
\begin{aligned}
& \psi^{\prime \prime}(x)+\frac{1}{\lambda^{2}} \psi(x)=0, \\
& \ddot{\varphi}(t)+\frac{\dot{x}^{2}(t)}{\lambda^{2}} \varphi(t)=0 .
\end{aligned}
$$

Let us introduce the dimensionless quantity $\tau=\sqrt{\omega_{0} \omega} t$; as a result, we obtain:

$$
\ddot{\varphi}(\tau)+\frac{\vartheta_{0}{ }^{2}}{\omega^{2} \lambda^{2}}\left(\frac{\omega}{\omega_{0}}-\tau^{2}\right) \varphi(\tau)=0 .
$$

Thus, it follows from Eq. (38) that for harmonic oscillator when the object motion speed as a function of time and object motion trajectory are known and wave function is superimposed on the trajectory, we get discrete energy values, just as in the Schrödinger case [12], [13] for harmonic oscillator.

Now let us apply the $V$-function method:

$$
\dot{x}^{2}=\frac{2 E-k x^{2}}{m} \text {. }
$$


With allowance made for Eq. (39) it becomes:

$$
\frac{\partial^{2} V}{\partial t^{2}}-\left(\frac{2 E-k x^{2}}{m}\right) \frac{\partial^{2} V}{\partial x^{2}}=0
$$

The following equations are obtained from Eq. (40) after separation of variables:

$$
\begin{aligned}
& \varphi^{\prime \prime}+\omega^{2} \varphi=0, \\
& \psi^{\prime \prime}+\frac{m \omega^{2}}{2 E-k x^{2}} \psi=0 .
\end{aligned}
$$

Let us introduce a dimensionless quantity $\xi=\frac{x}{\sqrt{\frac{2 E}{k}}}$; then Eq. (42) is:

$$
\psi^{\prime \prime}+\frac{\eta^{2}}{1-\xi^{2}} \psi=0
$$

where

$$
\eta^{2}=\frac{m \omega^{2}}{k}=\frac{\omega^{2}}{\omega_{0}^{2}}
$$

We apply the computer mathematics system Maple to solve Eq. (43). Its solution is:

$$
\psi(\xi)=C_{1}\left(\xi-\xi^{3}\right) \text { hypergeom }\left(\left[\frac{5}{4}+\frac{1}{4} \sqrt{4 \beta^{2}+1}\right],\left[\frac{5}{4}-\frac{1}{4} \sqrt{4 \beta^{2}+1}\right],\left[\frac{3}{2}\right], \xi^{2}\right) .
$$

The solution of Eq. (42) in this system is as a series:

$$
\begin{aligned}
& \psi(x)=\frac{1}{E} C_{1} x\left(E-\frac{k x^{2}}{2}\right)\left(1+\frac{1}{12} \frac{6 k-m \omega^{2}}{E} x^{2}+\frac{1}{480} \frac{\left(6 k-m \omega^{2}\right)\left(20 k-m \omega^{2}\right)}{E^{2}} x^{4}+\right. \\
& \frac{1}{40320} \frac{\left(6 k-m \omega^{2}\right)\left(20 k-m \omega^{2}\right)\left(42 k-m \omega^{2}\right)}{E^{3}} x^{6}+ \\
& \left.\frac{1}{5806080} \frac{\left(6 k-m \omega^{2}\right)\left(20 k-m \omega^{2}\right)\left(42 k-m \omega^{2}\right)\left(72 k-m \omega^{2}\right)}{E^{4}} x^{8}+\ldots\right)
\end{aligned}
$$


It follows from Eq. (46) that continuous solution $\psi(x)$ has to satisfy the condition $\psi\left(x=\sqrt{\frac{2 E}{k}}\right)=0$ This condition is fulfilled only at certain discreet values of proper frequencies: $\eta_{1}^{2}=\frac{\hbar^{2} \omega_{1}^{2}}{\hbar^{2} \omega_{0}^{2}}=6, \eta_{2}^{2}=\frac{\hbar^{2} \omega_{2}^{2}}{\hbar^{2} \omega_{0}^{2}}=20, \eta_{3}^{2}=\frac{\hbar^{2} \omega_{3}^{2}}{\hbar^{2} \omega_{0}^{2}}=42, \eta_{4}^{2}=\frac{\hbar^{2} \omega_{4}^{2}}{\hbar^{2} \omega_{0}^{2}}=72, \cdots$

From this we get the following rule of energy quantization for harmonic oscillator:

$$
E_{n+2}^{2}-2 E_{n+1}^{2}+E_{n}^{2}=\Delta \quad E_{n}^{2}=2 \hbar^{2} \omega_{0}^{2}
$$

Therefore, when the trajectory motion of an object is closely related to the wave motion, the harmonic oscillator energy can have, as in the Schrödinger case, only certain discrete values: $E_{1}^{2}=6 \hbar^{2} \omega_{0}^{2}, E_{2}^{2}=20 \hbar^{2} \omega_{0}^{2}, E_{3}^{2}=42 \hbar^{2} \omega_{0}^{2}, E_{4}^{2}=72 \hbar^{2} \omega_{0}^{2} \ldots$.

In this case, if the results obtained by Schrödinger $\left(E_{n}=\left(n+\frac{1}{2}\right) \hbar \omega_{0}\right)$ are substituted into equality Eq. (47), then we have:

$$
\left(\left(n+2+\frac{1}{2}\right)^{2}-2\left(n+1+\frac{1}{2}\right)^{2}+\left(n+\frac{1}{2}\right)^{2}\right) \hbar^{2} \omega_{0}^{2}=2 \hbar^{2} \omega_{0}^{2},
$$

i.e., we get an identity. It is known [14], [15] that in real microscopic oscillators interacting with light only transitions between the adjacent levels can occur.

It should be noted that a Wronskian for Eq. (43) is a nonzero constant, i.e., from this we get the second linearly independent solution

$$
\begin{aligned}
& \frac{\psi_{n}(\xi) \widetilde{\psi}_{n}^{\prime}(\xi)-\widetilde{\psi}_{n}(\xi) \psi_{n}^{\prime}(\xi)}{\left(\psi_{n}(\xi)\right)^{2}}=\left(\frac{\widetilde{\psi}_{n}(\xi)}{\psi_{n}(\xi)}\right)^{\prime}=\frac{\tilde{N}}{\left(\psi_{n}(\xi)\right)^{2}} \Rightarrow \\
& \widetilde{\psi}_{n}(\xi)=C \psi_{n}(\xi) \int \frac{1}{\left(\psi_{n}(\xi)\right)^{2}} d \xi .
\end{aligned}
$$

It follows from relations that $\left|\psi_{n}(\xi)\right| \rightarrow \infty$ as $\xi \rightarrow \infty$. Thus, we obtain from Eq. (50) that $\widetilde{\psi}_{n}(\xi) \rightarrow 0$ as $\xi \rightarrow \infty$, i.e., the solution is finite at infinity.

\section{CONCLUSIONS}

Using the $V$-function method, we get that particle uniform motion with constant speed is joined with wave motion. The obtained wave function has to 
satisfy the classical wave equation. In this case, if the wave function ( $V$-function) has dimension of action $([\mathrm{kg}][\mathrm{m} / \mathrm{s}][\mathrm{m}])$, then particle energy takes certain discrete values. The quantization law becomes the same as the Schrödinger energy quantization law for harmonic oscillator.

Thus, based on the $V$-function method, any trajectory motion of an object is inseparably linked with its wave motion. We have considered both direct and inverse problems for the case of particle uniform motion with constant speed. The optomechanical analogy is made and accordance between wave and particle is obtained. Here the main factor is equality of phase speed of wave and speed of particle motion.

In the case of harmonic oscillator when trajectory motion of particle is not related to wave motion, the Schrödinger equation for harmonic oscillator results. If trajectory equation is inseparably linked with wave equation, then we get the energy quantization rule linking three adjacent levels. This is in agreement with the real microscopic oscillators interacting with light. The finite solutions for harmonic oscillator are also obtained.

\section{REFERENCES}

1. Heisenberg, W. (1930). Die Physikalischen Prinzipien der Quantentheorie. Leipzig: Springer.

2. Bloch, A.M., \& Rojo, A.G. (2016). Optical mechanical analogy and nonlinear nonholonomic constraints. Physical Review E, 93(2), 023005. DOI: 10.1103/ PhysRevE.93.023005

3. Abdil'din, M.M., Abishev, M.E., Beissen, N.A., \& Taukenova, A.S. (2011). On the optical-mechanical analogy in general relativity. Gravitation and Cosmology, 17(2), 143-146.

4. Khan, S.A. 2017. Hamilton's optical-mechanical analogy in the wavelength-dependent regime. Optik - International Journal for Light and Electron Optics, 130, 714-722.

5. De Broglie, L. (1967). Waves and quanta. Quanta of light, diffraction and interference. Quanta, the kinetic theory of gases and the Fermat principle. Advances of Physical Sciences, 93(1), 178-180.

6. De Broglie, L. (1986). The Heisenberg uncertainty relations and the probabilistic interpretation of wave mechanics. Moscow: Mir.

7. Böhm, D. (1951). Quantum Theory. Englewood Cliffs: Prentice-Hall.

8. Knoll, Y., \& Yavneh, L. (2006). Coupled wave-particle dynamics as a possible ontology behind Quantum Mechanics and long-range interactions. arXiv:quant-ph/0605011. Available at: http://citeseerx.ist.psu.edu/viewdoc/download?doi=10.1.1.252.7980\&rep= rep1\&type $=$ pdf

9. Valishin, F.T. (2018). The problem of the beginning and the strategy of dynamism. Moscow: Entsiklopedist-Maksimum.

10. Valishin, N.T. (2014). Variational principle and the problems dynamics. Life Science Journal, 11(8), 568-574.

11. Valishin, N.T. (2016). An optical-mechanical analogy and the problems of the trajectorywave dynamics. Global Journal of Pure and Applied Mathematics, 12(4), 2935-2951.

12. Schrödinger, E. (1926). Quantisierung als Eigenwertproblem. Annalen der Physik, 384(4), 361-376. 
13. Schrödinger, E. (1959). Quantization as a problem of eigenvalues. In: Variational Principles of Mechanics. Digest of Articles (pp. 668-704). Moscow: Fizmatgiz.

14. Goldin, L.L., \& Novikova, G.I. (2002). Quantum physics. Introductory course. Moscow: Institute for Computer Research.

15. Syzrantsev, V.N., Chelombitko, S.I., \& Gammer, M.D. (2018). The use of virtual laboratory works in the study of engineering disciplines of oil and gas training. Periódico Tchê Química, 15(30), 563-570.

\title{
V-FUNKCIJAS METODE: DAŽI TIEŠĀ UN APGRIEZTĀ DINAMIKAS UZDEVUMU RISINĀJUMI JAUNĀ IZKLĀSTĀ
}

\author{
N. T. Vališins, F. T. Vališins
}

Kopsavilkums

Pamatojoties uz V-funkcijas metodi, objekta kustības viḷnu rakstura īpašības pētîtas objekta vienādas kustības ar nemainīgu ātrumu un harmoniskā oscilatora mērķim. No V-funkcijas metodes izriet, ka objekta vilı̧nu kustība ir nesaraujami saistîta ar trajektorijas kustību. V-funkcijas metode iekḷauj vietējās variācijas principu un jaunu tiešā un apgrieztā dinamikas uzdevumu izklāstu. Ierosinātā pieeja l̦āva veikt optisko un mehānisko analog̣iju, kas ieguva jaunu turpinājumu. Salīdzinājums veikts ar rezultātiem, ko Šrēdingers ieguva attiecībā uz harmonisko oscilatoru.

17.12.2018. 